\title{
The Meanings of Fictional Names
}

\author{
Fiora Salis*
}

Received: 19 May 2020 / Accepted: 23 November 2020

Abstract: According to Millianism, the meaning of a name is exhausted by its referent. According to anti-realism about fictional entities, there are no such entities. If there are no fictional entities, how can we explain the apparent meaningfulness of fictional names? Our best theory of fiction, Walton's theory of make-believe, makes the same assumptions but lacks the theoretical resources to answer the question. In this paper, I propose a pragmatic solution in terms of two main dimensions of meaning, a subjective, psychological dimension and an intersubjective, public dimension. The psychological dimension builds on the notion of mental files; the public dimension builds on Stalnaker's notion of common ground. The account is coherent with two main theoretical principles, parsimony and uniformity. Furthermore, it satisfies three explanatory conditions posed by the intentionality of our thought and discourse about fiction, object-directedness, counterfictional imagining and intersubjective identification.

Keywords: Fictional names, mental files, common ground, make-believe, Mill, Walton, Stalnaker.

* The University of York

(D) https://orcid.org/0000-0001-8258-0587

Department of Philosophy University of York, Heslington, York UK YO10 5DD.

$\triangle$ fiora.salis@york.ac.uk

(c) The Author. Journal compilation (C) The Editorial Board, Organon F.

This article is distributed under the terms of the Creative Commons Attribution-NonCommercial 4.0 International Public License (CC BY-NC 4.0). 


\section{Introduction}

I assume that there are no fictional entities of any peculiar kind, no fictional people, no fictional places and no fictional objects. Yet, we talk about Desdemona, Middle-earth, Hop-o'-My-Thumb and the magic Seven League Boots. For example, we say that Desdemona is a Venetian beauty, that Middle-earth is the central continent on Earth, that Hop-o'-My-Thumb steals the Seven League Boots from the sleeping giant. If there are no fictional entities, how can we explain the apparent meaningfulness of fictional names such as 'Desdemona,' 'Middle-earth,' 'Hop-o'-My-Thumb,' and 'Seven League Boots'? This is the question I want to address in this paper.

Fictional names are names of the same semantic type as proper names, such as my name and your name, names of places such as 'Barcelona', names of things such as 'the Hindenburg'. Proper names are expressions that refer to something or at least are used under the presupposition that they refer to something. The philosophical debate on the semantics of proper names ideally divides in two main streams. The first started with Mill (1843), who considered the contribution of a proper name to language exhausted by its individual referent. According to standard versions of this view, understanding the meaning of a name comes down to some direct causal epistemic relation to its individual referent. The second was roughly initiated by Frege (1892), who argued that the contribution of a proper name to language is some kind of descriptive information that determines the referent of a name, if any. According to this view, understanding a name consists in grasping the relevant descriptive information. Correspondingly, there are two main views on the semantics of fictional names. According to Millianism, fictional names contribute their referents, if any, to the truth conditions of sentences containing them. According to descriptivism, they contribute properties and relations that determine their referents, if any. I assume that there are no fictional entities, hence names such as 'Desdemona' are referring expressions without referents. Nevertheless, I will argue that the correct semantics for discourse about fictional characters is Millian.

There are two standard objections against Millianism for names without referents, which regard the apparent meaningfulness of empty names and the meaningfulness of sentences containing them. The problem of the 
meaningfulness of names is based on the premise that if someone understands a name, then she knows its semantic content. But names without referents have no semantic content. If fictional names have no referents and Millianism is true, they have no meaning. Yet, ordinary speakers judge them to be fully meaningful. Therefore, Millianism for names without referents must be false. The problem of the meaningfulness of sentences is based on the premise that if someone understands a sentence containing a name, then she knows its semantic content. But names without referents contribute nothing to the semantic content of sentences. If names like 'Desdemona' contribute nothing to the semantic content of sentences, and Millianism is true, then sentences containing them have no semantic content either. Yet, speakers judge them to be fully meaningful. Therefore, Millianism for names without referents must be false.

Standard solutions to the problem of the meaningfulness of sentences appeal to gappy propositions (Adams and Stecker 1994; Braun 2005; Friend 2011; Salis 2013a). The idea is that sentences containing non-referring names express incomplete propositions that are structurally similar to fully fledged propositions. On this proposal, a sentence such as 'Desdemona was a Venetian beauty' expresses an incomplete proposition having a gap in subject position and a property in predicate position, canonically represented as $<\ldots$, being-a-Venetian-beauty $>$. Obviously, the main advantage of gappy proposition theories is that they preserve the structural similarity between sentences involving referring names and those involving non-referring names. The main disadvantage is that they do not have the theoretical resources to distinguish between different sentences intuitively having different meanings (and truth-conditions) but expressing the same gappy proposition, e.g., 'Desdemona was a Venetian beauty' and 'Othello was a Venetian beauty.' Something else must be key to an explanation of this datum. Proponents of gappy proposition theories usually build on solutions they offer to the problem of the meaningfulness of names.

Standard solutions to the problem of the meaningfulness of names have been put forward in terms of further types of meaning at the cognitive level. ${ }^{1}$ These solutions distinguish between the semantic content of linguistic

1 Millianism can be interpreted as a particularly strong version of referentialism, the view according to which the semantic contribution of a name is its referent, if it 
expressions, including names, and the cognitive relations speakers bear to names. The idea is that ordinary speakers bear cognitive relations to nonreferring names that are similar to those they bear to referring names. On one such proposal, the relevant type of similarity is cast in terms of the causal relation with information inputs, mental states and behavioural outputs (Braun 2005). On a slightly different proposal, the relevant type of similarity is cast in terms of the notion of mental files, which are cognitive representations of (real or fictional) individuals (Friend 2011, 2014; Salis 2013a). Coherently with Millianism, mental files involve qualitative information associated to names or other singular linguistic expressions that contribute to the cognitive meaning associated to names but not to their semantic content. The main advantage of these proposals is that they preserve the intuitive similarities between thoughts about concrete objects and fictional objects, independently of any ontological commitment to their existence. The main drawback is that by locating the explanation of the meaningfulness of names in the mind of speakers, these proposals risk to undermine the intersubjective construction of meaning that is essential to our engagement with works of fiction. Effectively, these solutions are psychologistic in spirit. ${ }^{2}$

In this paper I want to develop a pragmatic account of the meaningfulness of fictional names that combines two aspects of meaning, social - or intersubjective - and psychologistic - or subjective. The underlying assumption is that fiction is a communicative effort, namely a social interaction between an author (or, possibly, group of authors) and an audience. Key to this account is the recognition that fictional names are introduced in works

has one. Alternative, more liberal versions of referentialism recognise that proper names can have further dimensions of meaning, including linguistic, cognitive, and pragmatic, that are also truth-conditional. For example, Perry's (2001) critical referentialism submits that an utterance of a proper name comes equipped with a conventional reflexive content that makes reference to the utterance itself. I don't have the space to discuss this (or similar proposals) here. But I invite the reader to have a look at Salis (2013a) for a critical discussion of Perry's information based account of the meaning of empty names, which is integral to his critical referentialism.

2 See Maier (2017) for a recent development of a fully psychologistic semantics of fictional discourse that is inspired by Kamp (1990) and relies on the analogous notion of internal anchors. 
of fiction that function as scaffolding for the construction of intersubjective meaning. The best account of fiction is Walton's (1990) theory of fiction as a game of make-believe. This theory, however, does not offer any solution to the problem of the meaning of fictional names. Following Stalnaker (2002), I will argue that the social, intersubjective dimension of meaning can be spelled out in terms of the notion of common ground. ${ }^{3}$ This social dimension can be integrated with a psychologistic, subjective dimension of meaning spelled out in terms of the notion of mental files. On this view, fiction is a form of social interaction that effects the mental representations of its consumers. The author of fiction tells a story that encourages certain imaginings via the use of intersubjectively available linguistic tools. These tools are created for the purpose of encouraging imagining in certain ways and provide the manifest basis for the acquisition of information that can be shared by consumers of fiction and stored in mental representations.

\section{What account of fictional names?}

Addressing the key question of this paper requires that we first identify the criteria by which we want to evaluate a theory of fictional names. The most important criteria are two theoretical requirements, parsimony and uniformity, and three explanatory conditions, object-directedness, counterfictional imaginings, and intersubjective identification. Let us begin by considering the theoretical requirements.

According to the theoretical principle of parsimony, we should reject any unnecessary commitment to the existence of fictional entities. We face the initially intuitive datum that fictional entities do not exist as ordinary physical objects. For example, we say that Desdemona does not exist and that Middle-earth is just a fiction. Depending on the interpretation we give of this datum, we divide between realists and antirealists about fictional entities. Fictional antirealists take the nonexistence datum at face value

3 Geurts (2017) suggests that fiction is a form of communication and describes the possibility of developing what he calls an ecumenical account (one that combines interpersonal and psychologistic dimensions of meaning) in terms of negotiating commitments. 
and argue that there are no fictional entities (Everett 2007, 2013; Sainsbury 2010; Walton 1990). Fictional realists believe that there are fictional entities and explain the nonexistence datum in different ways depending on their preferred metaphysics of fiction. Upholders of fictional Meinongianism distinguish between being and existence and argue that there are non-existent objects (Berto 2011; Castañeda 1990; Priest 2005; Rapaport 1978; Voltolini 2006). Abstract object theorists posit a difference between concrete and abstract existence and argue that fictional entities are abstract entities that do not exist as concrete objects (Currie 1988, 1990; van Inwagen 1977; Thomasson 1999). Fictional possibilists argue that fictional entities are merely possible objects that do not exist at the actual world (Lewis 1978, 1986).

The debate on the ontology of fiction is ripe with controversy and none of the linguistic and ontological arguments that fuel the ongoing discussion between realism and antirealism is conclusive. ${ }^{4}$ There is, however, one theoretical consideration that, in my opinion, trumps realism. Whatever data realists about fictional entities present, antirealists can provide equally plausible explanations that avoid ontological commitment to fictional entities. If there are alternative plausible explanations of the same data that do not require the postulation of disputed entities, then there is no need to commit to their existence. That is, fictional entities are dispensable. In particular, as I will argue, we do not need them to account for the meaningfulness of fictional names.

According to the theoretical principle of uniformity, fictional names have the same meaning across different types of discourse about fiction. It is common to distinguish between two main types of fictional discourse, intrafictional and extra-fictional. Intra-fictional discourse is discourse we perform from within the fiction, from a participatory or internal perspective. This kind of discourse is commonly interpreted as involving a mental attitude of imagination and a conniving use of language, one wherein the utterer engages in pretence or make-believe. ${ }^{5}$ For example, in storytelling and in reports about the content of fictional stories we say that Desdemona was a Venetian beauty and that Middle-earth is the central continent on Earth.

4 See Salis (2013b) for a detailed review of these disputes.

5 The expression 'conniving' was introduced by Evans (1982).

Organon F 28 (1) 2021: 9-43 
Extra-fictional discourse, on the other hand, is the sort of discourse we perform from without the fiction, from a descriptive or external perspective. In this case, we assume an attitude of belief and we perform a non-conniving use of language, one wherein the utterer engages in serious assertion that can be assessed for truth and falsity. For example, in meta-fictional discourse we believe that, according to Shakespeare's Othello, Desdemona was a Venetian beauty. Other types of discourse about fictional characters raise disputes between realists and antirealists. Realists usually construe literary criticism as extra-fictional discourse and claim that such discourse is committed to the existence of fictional entities. Among their favourite examples are sentences such as 'Desdemona is a fictional character', or 'Desdemona was created by Shakespeare', which seem to be straightforwardly true. Antirealists reject this interpretation and extend the notion of intra-fictional discourse to literary criticism in ways that I will explain in the next Sections.

There are two main accounts of the meaning of fictional names in intrafictional and extra-fictional discourse, mixed and uniform. According to the mixed account, fictional names are rigid non-designators (they have no referent, neither actual nor possible) when uttered by the author of fiction in intra-fictional discourse; they are rigid designators (they refer to the same entity in all possible worlds) when used by readers and critics in extrafictional discourse that seem to commit us to the existence of fictional entities (Currie 1988, 1990; Kripke 1980, 2013; Van Inwagen 1977). The first use is ontologically foundational (it is the use through which fictional entities are created or selected among the range of fictional objects). The second use is parasitic on the first.

Mixed accounts face some well-known internal problems, which I won't have space to rehearse here. ${ }^{6}$ Moreover, there is linguistic evidence against the purported ambiguity in the different uses of fictional names. For example, we can say in one and the same breath that Desdemona was the daughter of Brabantio and a fictional character. This sentence is naturally interpreted as involving the attribution of two properties (being-the-daughterof-Brabantio and being-a-fictional-character) to the same individual

$6 \quad$ See Salmon (1998) for influential criticisms. 
(Desdemona). The mixed account would have us interpret the only instance of the name 'Desdemona' in two ways, as a rigid non-designator (with respect to the first property) and as a rigid designator (with respect to the second property). We, however, do not seem to make any such distinction. To reinforce this point, consider an analogous example where we say that Amie Thomasson is an American philosopher and a fictional character. This sentence is naturally interpreted as involving the attribution of two properties (being-an-American-philosopher and being-a-fictional-character) to the same individual (Amie Thomasson). This interpretation is as natural as the previous one. In each case, it seems that we are attributing different properties to one and the same individual. The postulated ambiguity of meaning in different uses of the same fictional name seems artificial and not backed up by the evidence.

Mixed accounts have been rejected as unnecessary by upholders of uniform accounts of fictional names, according to which fictional names have the same meaning in all discourse about fiction. Proponents of uniform accounts divide between fictional realists and fictional antirealists. Realists hold that fictional names are rigid designators referring to fictional entities since their first use in storytelling (Salmon 1998; Thomasson 1999). ${ }^{7}$ Antirealists hold that fictional names are non-rigid designators throughout discourse about fiction (Walton 1990; Everett 2007, 2013). Uniform accounts offer a uniform semantics for fictional names according to which the name 'Desdemona' is a rigid designator (realism) or a rigid non-designator (antirealism) throughout its different uses.

Realist uniform accounts seem to fare better than antirealist accounts with respect to the three explanatory conditions that a theory of fictional

7 Salmon argues that once one accepts that there are fictional entities, one better interprets uses of fictional names as referring to those entities. As he puts it: 'Once fictional characters have been countenanced as real entities, why hold onto an alleged use of their names that fails to refer to them? It is like buying a luxurious Italian sports car only to keep it garaged' (1998, 298). Similarly, Thomasson (1999) argues that storytelling is a sort of special performative speech act that immediately brings a fictional character into existence. Once the character is created, all uses of the name by the author in the story and by readers and critics refer back to the character.

Organon F 28 (1) 2021: 9-43 
names must satisfy, object-directedness, counterfactual imaginings, and intersubjective identification. These conditions emerge from Friend's (2011, 2014) considerations on the intentionality of our thought and discourse about fictional characters that upholders of fictional realism (in particular, Thomasson 1999) adduce in favour of the postulation of fictional entities. Effectively, these conditions pose a problem for upholders of antirealism.

Let us begin by considering object-directedness. Thoughts about Desdemona seem to be about Desdemona, not about Othello or Iago. They function like singular thoughts that are about a particular individual rather than about whoever is the Venetian beauty, daughter of Brabantio, and wife of Othello. In other words, when we think about Desdemona, we think about the fictional character herself rather than about whoever satisfies the set of descriptions associated to her name in the story. Realists can argue that it is by recognising the existence of fictional characters that we can account for the object-directedness of our thoughts about them. After all, how could our thoughts about Desdemona be about any particular individual if there is no Desdemona?

Second, we can engage in counterfictional imaginings about fictional characters, which involve a change in their properties. I can imagine that Desdemona may have had a different faith had she not met Othello, or that Middle-earth may have been a continent in the southern hemisphere. In these cases, we seem to imagine a particular entity as having properties that it does not really have. Realists can explain this phenomenon by postulating that our imaginings are about objects we can identify independently of the properties they have in the world of the story. But how could antirealists account for the same phenomenon if there are no fictional entities?

Third, we can intersubjectively identify characters even when we disagree about their properties. Was Hedda Gabler a victim of society, as a standard feminist interpretation suggests, or was she a true descendant of Iago and Edmund, as Harold Bloom (1999) has it? Did Hamlet suffer from an Oedipus complex, as suggested by Freud, or was he one of Shakespeare's hero-villains, as argued by Bloom (2001)? Realists can explain this datum by postulating the existence of a fictional entity we can intersubjectively identify and disagree about. In fact, how could we intersubjectively 
identify something that does not exist when we attribute different properties to it?

In the rest of this paper, I will develop a pragmatic account of the meaning of fictional names that is coherent with parsimony and uniformity and that can satisfy the three explanatory conditions of intentionality.

\section{Walton's fictions}

Standard theories of fiction characterise it in terms of an invited response of imagination or make-believe. ${ }^{8}$ Most upholders of this view define works of fiction in terms of a characteristic speech act of fictionalising - or fictive utterance - that would distinguish it from non-fiction (Currie 1990; Davies 1996; Lamarque and Olsen 1994; Stock 2011, 2017). A fictive utterance is defined in terms of a Gricean intention. The idea is that an author intends readers of fiction to imagine certain things, and that readers of fiction recognise this very intention and imagine accordingly. In contrast, non-fiction is defined in terms of an author's speech act of assertion that invites belief. These proposals are inspired by Walton's (1990) theory of fiction as make-believe. Walton himself, however, rejects the idea that fiction be defined in terms of an author's intention and suggests instead that an author's storytelling involves mere pretend assertions. While I sympathise with Gricean approaches to fiction, nothing much will hinge on whether we interpret the act of storytelling as a genuine speech act or as an act of pretend assertion here.

Central to Walton's account of the nature of fiction is a fruitful analogy with children's games of make-believe. On this proposal, make-believe is a social imaginative activity constrained by the use of props. Sometimes we imagine something without a particular reason. But some other times our imaginings are prompted by the presence of a particular object, in which case this object is referred to as a prop. Props are ordinary objects that

8 An exception is Friend (2012) who argues that fiction should be defined in terms of the relational, historical notion of genre. García-Carpintero (2013) replies, correctly in my view, that Friend's argument fails to demonstrate that imagination is unnecessary to a characterisation of fiction.

Organon F 28 (1) 2021: 9-43 
make propositions fictional in virtue of there being a prescription to imagine something. Walton argues that any ordinary object can become a prop in virtue of the imposition of a rule, or principle of generation, prescribing what is to be imagined when presented with the object. If someone imagines something because she is encouraged to do so by the presence of a prop, she is engaged in a game of make-believe, and someone who is engaged in a game of make-believe is engaged in the activity of pretence.

It is natural to spell out the notion of truth in fiction - or fictionalityin terms of fictional worlds. The idea is that in telling a fictional story, the author indicates or creates a fictional world that readers and critics subsequently explore through their imagination. To be true in the fiction is to be true in the world of the story. Some take this interpretation literally and argue that fictional truth is a variety of truth and that being fictionally true is being true at a possible (Lewis 1978) or impossible (Berto 2011; Priest 1997) world. On this view, utterances about fictional characters are genuine assertions that can be assessed for truth and falsity throughout different varieties of fictional discourse. Others, including Walton (1990), reject this idea and argue that fictional truth is not a variety of truth. Rather, it is a property of the propositions that are among the prescriptions to imagine in force in a fictional story. On this interpretation, utterances about fictional characters are pseudo assertions that can only be correct or incorrect. ${ }^{9}$ Both proposals face some well-known internal problems that we will have no space to discuss here. ${ }^{10}$ Most importantly, however, the former typically underestimates the role of imagination in fiction and it naturally combines with a realist interpretation of fictional entities.

So, on Walton's notion, fictionality is a property of the propositions that are among the prescriptions to imagine of a certain game. The statement 'it is fictional that $p$ ' is to be understood as 'it is to be imagined that $p$ '. In this sense, Walton's notion of fictionality is both normative (it depends on the stipulation of rules that guide the imaginings of participants in the game) and objective (it is independent of the idiosyncratic imaginings of individual participants who may or may not imagine in conformity with a game's prescriptions). Moreover, fictional truths divide into primary truths

$9 \quad$ See Eagle (2007) and Currie (1990) for similar views.

10 See Woodward (2011) for a critical overview.

Organon F 28 (1) 2021: 9-43 
and implied truths, where the former generate from the original prescriptions to imagine while the latter generate indirectly from the primary truths via further principles of generation.

In one of Walton's favourite examples, children play a game where they pretend that tree stumps are bears. In this game, tree stumps are props that prescribe certain imaginings in virtue of the original prescription to imagine (that tree stumps are bears) and further principles of generation. So, for example, when children see a tree stump in the woods, they imagine that there is a bear in the woods, and if someone lassoes a tree stump, they imagine that someone catches a bear. Furthermore, some imaginings may be shared by all participants in the game, while others may not. If there is a tree stump hidden behind a bush and nobody can see it, it will be fictional that there is a bear hidden behind the bush even if nobody imagines so. Walton calls this type of game of make-believe unofficial, in the sense that the rule that generates it is ad hoc. Other games, however, involve stable and conventional rules and for this reason Walton calls them authorised. These games involve props that have been created for the purpose of prescribing certain publicly recognised imaginings. For example, hobby horses and babydolls prescribe imagining horses or babies respectively. Props that have been originally introduced in authorised games of make-believe are what Walton calls 'representations'.

Walton argues that the ability to engage in games of make-believe does not disappear when we become adults. In fact, he encourages us to interpret representational works of art, including literary works of fiction, as props that have been originally created for the purpose of generating certain games of make-believe. Literary works of fiction, in particular, are syntacticsemantic entities that can be perceived through concrete copies of texts in printed, digital or audio versions. They prescribe certain imaginings in virtue of an author's prescriptions. When reading What Masie Knew, we imagine that Masie lives in London in virtue of Henry James' prescription to imagine that this is the case. Further truths in the fiction can be generated from the primary truths via two main principles, the reality principle and the mutual belief principle. The reality principle keeps the world of the fiction as close as possible to the real world. From the primary fictional truth that Masie lives in London and our knowledge of Europe's geography, 
we can infer the implied fictional truth that Masie's trip to France requires travelling on the Dover Calais ferry route. The mutual belief principle generates further implied truths by importing the mutual beliefs of members of the community in which the story originated. Many implied truths in Homer's Iliad are generated against the ancient Greek mythological beliefs. While Walton does not explicitly recognise it, others have already noticed that make-believe has the flexibility to include further principles of generation that may depend on particular genres and literary conventions. Of course, there are cases where determining what is fictional is difficult. For example, did Edna, the main character in Chopin's The Awakening, die by purposefully committing suicide or did she unintentionally got swept away in the waves? Did the governess in James' The Turn of the Screw really see the ghosts of Miss Jessell and Peter Quint, or was she of unsound mind? Importantly, our appreciation of these stories may depend on the fact that the ambiguity cannot be solved. But in the vast majority of cases, we have a clear grasp of what is true in the fiction and what is not.

Someone who imaginatively engages with literary works of fiction plays an authorised game of make-believe. This is often the case in intra-fictional discourse such as producing reports about the content of the story. There are, however, other ways of developing a story within the imagination that constitute unofficial games of make-believe and can therefore be interpreted as further examples of intra-fictional discourse. A typical case is offered by literary critics' practice of exploring a character's properties from a participatory perspective, as the natural continuation of stories, sometimes even in cross-fictional contexts. In these instances, critics talk about characters as if they were real, by predicting their behaviour, their thoughts, their feelings, comparing them to other characters and so on. Harold Bloom, reflecting on Hedda Gabler, the character, writes:

Whether commanding an army or an arms factory, Hedda would have acted like her forerunners Iago and Edmund. Her genius, like theirs, is for negation and destruction ... her intelligence is malign, not because of social circumstances but for her pleasure, for the exercise of her will. (quoted in Eagle 2007, 128)

Although this kind of imaginings are the result of Bloom's development of the story from a participatory perspective, none of them is among the 
imaginings prescribed by the author or implicitly derivable from the story. They are moves in an unofficial game of make-believe.

Walton's proposal fits well with the two theoretical principles of parsimony and uniformity. It is ontologically parsimonious because while his framework is compatible with both realism and antirealism about fictional entities, Walton voices his preference for an antirealist account of fiction. Games of make-believe can involve imaginings about real objects and fictional objects. But imaginings do not commit us to postulate any fictional entities. Imagining a flying donkey does not commit one to the existence of a flying donkey. Moreover, the account is uniform because Walton suggests that fictional names are rigid non-designators in all their uses. He assumes a Millian account of names and recognises that fictional names have no referents and cannot contribute anything to the truth conditions of sentences. In fact, Walton argues that statements involving fictional names express no propositions and have no truth-conditional content. On this view, they are not descriptions of states of affairs but prescriptions to imagine in certain ways.

Walton's analysis inherits the problems of a Millian semantics for fictional names and it therefore fails to satisfy the explanatory conditions of object-directedness, counterfictional imaginings, and intersubjective identification. How can our thoughts and discourse about Hedda Gabler or any other fictional character be directed at any particular individual if Hedda does not exist? How can we imagine that Desdemona might have been different from the way she is in Shakespeare's Othello if there is no Desdemona? And how can we intersubjectively identify and even disagree about the properties of a fictional character if there isn't one? In the next three sections, I will develop an answer to these questions within the make-believe framework by appealing to the notions of mental files and common ground.

\section{Mental files and the subjective meaning of names}

Recent accounts of fictional names coherent with Millianism and Walton's account of fiction build on the recognition of the cognitive, psychological and subjective meanings that speakers associate with names. A key 
notion in these accounts is that of a mental file. The notion is best introduced with an example.

Sally and Mary meet Harry at a party in the philosophy department. Harry has red hair; he wears blue jeans and a yellow shirt. Sally assumes that he is a philosopher. When Sally meets Harry, she forms a mental file $H_{S}$ collecting all information she takes to be true of Harry. $H_{S}$ is informed by the encounter, but it needs not involve exclusively information that is true of Harry. $H_{S}$ contains Sally's personal perspective on Harry, which can but need not be the same as the set of properties he satisfies. Sally does not realise that Harry is Australian (she does not recognise his accent), and she does not know that he is not a philosopher, but a neuroscientist. Her mental file differs from the set of properties satisfied by Harry in all these respects. Mary learns about Harry from a common friend, Bob, who tells her that he's going to take a friend, a neuroscientist called Harry, to the party. So, Mary forms a mental file $H_{M}$ of Harry before the party, through conversation with Bob. When Mary meets Harry, she already knows that he is a neuroscientist, but she also recognises his accent and adds the information that he's Australian to her file. Thus, the information she takes to be about Harry is partially different from the information Sally takes to be about Harry. Mary's and Sally's mental files $H_{M}$ and $H_{S}$ share some information (has red hair, wears blue jeans and a yellow shirt), but not other (is a neuroscientist, is Australian). Sally's and Mary's files are subjective and idiosyncratic in these respects.

Mental files are a philosopher's construct that is akin to that of a concept. ${ }^{11}$ They are organization structures for the storage of information that a subject takes to be about a concrete object represented as an individual rather than as the possessor of certain properties. ${ }^{12}$ Mental files can be formed in perception (like Sally's encounter with Harry) or in communication (like Mary's conversation with Bob). In both cases, there's a causal relation between the individual source of information (Harry), which can be direct (in perception) or indirect (in communication chains).

11 Murez and Recanati (2016) emphasise the conceptual nature of mental files.

12 Obviously, the notion of a cognitive representation is distinct and independent from Walton's notion of representation as a prop in an authorised game of makebelieve. 
Since their inception mental files have been deployed in accounts of nonreferring names. ${ }^{13}$ Many have argued that mental files can lack referents and that the information stored in a mental file does not commit one to the existence of any particular object (Friend 2011, 2014; Perry 2001; Recanati 2012). In fact, one may conjecture a sort of teleological argument for the possibility that mental files lack a referent. ${ }^{14}$ Mental files are produced by cognitive mechanisms that have survived because they are good at producing non-empty cognitive representations. An empty file counts as a mental file just like a malformed heart that cannot perform the function of pumping blood is nevertheless a heart. The French physicist Le Verrier hypothesised that there existed a planet called 'Vulcan' that was responsible for the observed perturbations in Mercury's orbit. Le Verrier theorised about Vulcan, he searched for it through astronomical observations and exchanged information and ideas with colleagues about Vulcan. He collected a large fund of information in a mental file about Vulcan, which really did not exist.

Something different, however should be told of mental files for fictional objects. In this case there does not seem to be anything corresponding to the idea of a malformation. Empty mental files of fictions may serve another function. As all other mental files, they are structures in which speakers store and organise information, but this is to track objects in pretence, as an exercise of the imagination. A mental file for Desdemona is formed while reading a copy of Shakespeare's play Othello. As I will argue in the next section, writing and reading fiction constitute a communicative effort in which mental files are formed even without a direct or indirect causal relation with the individual referent of the file. This type of causal relation is merely imagined. Something else, however, is needed to guarantee that different speakers engaging with the fiction form mental files about the same fictional individuals. I'll indicate my preferred solution to this issue in Section 6 .

Information contained in mental files can be construed as a list of predicates that a speaker takes as satisfied by the individual referent of the file.

13 Grice originally introduced the notion under the name 'dossier' in his Vacuous Names (1969).

14 A similar argument was proposed by Sainsbury (2005) in relation to his notion of individual concepts, which I take to be analogous to mental files. 
Predicates can be relational, and thus involve other mental files. As a consequence, two files could appear in each other's list. This happens, for instance, when a file involves a proper name. When Mary thinks that Harry is Bob's friend, she deploys two mental files, the mental file $H_{M}$ containing the information 'is Bob's friend', and the mental file $B_{M}$, which she associates to the name 'Bob'. Effectively, there can be a hierarchy of files, but the files themselves contain only information (predicates) about Harry and Bob. They are associated to singular terms without including them. Moreover, mental files are not constituted or identified by their predicates and corresponding properties. The properties are merely associated with the file, and information can be added to and deleted from the file without changing the file itself. The day after the party, Sally and Mary chat about Harry. Eventually Sally learns that Harry is a neuroscientist, not a philosopher. She therefore updates her fund of information about Harry. She deletes the predicate 'is a philosopher' and adds the predicate 'is a neuroscientist' to $H_{S}$.

As far as the information stored in the mental file can be updated, no specific information is essential to the identity of the file. However, there may be a persistent core of information about Harry that Sally will not withdraw and that may be essential to Harry. Sally's mental file, for instance, could preserve the information that Harry is human, that he is identical to himself, and that he is a concrete individual. But these are not properties that she can use to keep track of Harry or to distinguish him from other individuals. The information that she can use in these cases is probably inessential to Harry, which means that it can always be updated, subtracted or added through the history of the mental file. The fact that this kind of information is inessential makes it also inapt to be used to fix the referent of the file, and hence knowledge of the information stored in a mental file is not equivalent to knowledge of reference conditions. Perception and communication chains open a channel of information flow from object to subject, and the source of information is undoubtedly important, but there is no guarantee that the information is accurate. Hence, the notion of a mental file cannot be reduced to that of the information it contains.

Mental files work as modes of presentation of particular individuals, and so they play cognitive roles akin to Fregean senses. Hence, they contribute 
a solution to the problem of the cognitive significance of names, which is the problem of explaining how one can have different thoughts about the same object without realising that one is thinking about the same object. In Frege's classical example, one can think about Hesperus and Phosphorus in two distinct ways, as the morning star and as the evening star respectively, possibly without realising that one is thinking about the very same planet, Venus. Similarly, a reader of Stevenson's The Strange Case of Dr Jekyll and Mr Hyde can think about Dr Jekyll and Mr Hyde in two distinct ways, as the kind doctor and the evil creature, without initially realising that they are the very same person. The solution in terms of mental files is that the names 'Hesperus' and 'Phosphorus' are associated with two distinct mental files each containing the relevant piece of information. One can believe that Hesperus will rise in the morning without believing that Phosphorus will rise in the morning because the names are associated with mental files involving different information. Similarly, the names 'Dr Jekyll' and 'Mr Hyde' are associated with different mental files. One can imagine that Dr Jekyll is a kind doctor without imagining that Mr Hyde is a kind doctor. Fregean senses are classically interpreted as descriptive modes of presentation that enter into the propositional content of sentences involving the relevant names. Mental files, however, are not necessarily interpreted in this way. The explanation in terms of mental files works at the level of thought, where mental files are the subjective components of an individual's cognitive relation to a proposition (including a gappy proposition).

Like Fregean senses, mental files can also contribute an explanation to the problem of informative identities, which is the problem of explaining why it is informative to be told that Hesperus is Phosphorus, but not to be told that Hesperus is Hesperus; or why it is informative to be told that Dr Jekyll is Mr Hyde, but not to be told that Dr Jekyll is Dr Jekyll. There are two different accounts of this phenomenon based on two different operations on files, merging and linking. On the merging model, accepting an identity statement requires the unification of two files which become one (Strawson 1974). ${ }^{15}$ On the linking model, accepting an identity statement requires the connection between files that remain distinct. Many have argued that the

15 The term 'merging' is introduced by Millikan (2000). 
merging model is probably not adequate to describe the cognitive effects of many identity judgments. For example, Millikan (1997) argues that it would be risky to merge two files on the basis of an identity judgment that one may accept with less than $100 \%$ subjective probability, while the operation of linking may be less risky. Furthermore, the ability to distinguish between the different sets of information may be key to track objects and draw certain inferences. The ability to distinguish between Dr Jekyll and Mr Hyde purely in terms of their properties may be relevant to understand the battle between the good and the evil within Mr Jekyll. A better model would explain the phenomenon of informative identities in terms of the linking of a multiplicity of files for the same object or individual, in reality or in imagination.

Cases of recognition and identification show different things. First, they show that referents may be shared by different mental files. An agent who thinks of Hesperus may not know that it is identical to Phosphorus: she has two distinct files for the same individual object. Similarly, someone who imagines Dr Jekyll may not know that she is imagining Mr Hyde. Second, they show that referents cannot be changed: a mental file has its referent forever, if any. There are two reasons for this claim, internal coherence and misidentification. ${ }^{16}$ An individual object imposes certain conditions on the coherence of the information stored in its mental file. If the predicate 'is $F$ " belongs to the mental file for $x$, then 'is not $F$ ' cannot belong to the same mental file, otherwise we would have inconsistent information about the same individual. If the referent of a file could change, there would be no constraint on updating information. This is especially relevant when the attitude one has toward the information contained in the file is belief. Coherence and consistency, however, may not always be required in imagination. For instance, there may be a mental file for the round square, even though the information 'is round' and 'is not round' is contradictory.

Another reason why the referent of a file cannot change is misidentification. Suppose that Harry has a twin brother, Barry. Sally meets Harry first and forms an individual concept of him. Then she meets Barry, but she does not know that Barry is Harry's twin brother. Sally thinks that she

16 These considerations are based on Sainsbury's (2010) similar account of individual concepts, which are cognitive entities akin to mental files. 
meets Harry again. She falsely believes that the individual she meets is Harry, while in fact he is Barry. She sees Barry for some time, and never sees Harry again. Now, is Sally's mental file about Harry or about Barry? We have two options. Either we say that Sally's mental file of Harry has shifted its reference to Barry or we say that, when Mary meets Barry, she forms a new mental file with a different referent. The first option, on which an individual mental file can change its referent, requires that we fix the referent by application. But we cannot fix the referent ex novo each time we use a mental file because in this case we could not give a systematic account of error and misidentification. If each time we misidentify an object, we just change the referent of the mental file there is no misidentification. Mental files can have at most one referent. If the same mental file applies to $x$ and $y$, then $x=y$. If this were not the case, misidentification (and memory and recognition) could not be accounted for (barring confusion, of course).

In sum, mental files are cognitive representations of individual objects, if any, which function as Fregean modes of presentations. They contribute to explanations of well-known problems, including the cognitive significance of names, informative identities, recognition, identification and misidentification of (real and fictional) objects. As cognitive representations, however, they are also subjective and idiosyncratic components of the meaning of names. Hence, an appeal to mental files cannot contribute an explanation of the intersubjective, social dimension of the meaning of fictional names and of discourse involving them. It is now time to explore also this dimension.

\section{Common ground and the imaginative stance}

Storytelling is a communicative effort that involves two parties, the author of fiction and the audience. Successful communication requires that both author and audience share certain background information - or common ground. Stalnaker (1999) introduces an influential notion of common ground, which he bases on the concept of presupposition. Common ground is the body of information that is presumed to be shared by the participants in a discourse. Stalnaker (1973) gives a standard pragmatic characterisation 
of presupposition as a proposition that a speaker presupposes at a given time in a discourse and on the basis of which she is disposed to act as if she takes its truth for granted and as if her audience recognises that she is doing so. He further explains that to presuppose something is a propositional attitude with a social dimension:

To presuppose something is to take it for granted, or at least to act as if one takes it for granted, as background information-as common ground among the participants in the conversation. What is most distinctive about this propositional attitude is that it is a social or public attitude: one presupposes that $\phi$ only if one presupposes that others presuppose it as well. (Stalnaker 2002, 701)

In this section, I will argue that we should assume a similar notion of common ground and pragmatic presupposition to develop an account of the social, intersubjective meaning of fictional names.

The standard analysis of common ground is usually couched in terms of belief. Common ground is common belief and what a speaker presupposes is what she believes that others believe. Thus, common belief is a property of a group, while speaker presupposition is a propositional attitude of the individual speaker. The common beliefs of participants in a conversation are the beliefs that they believe others share. For example, when having a conversation with a colleague, I may say: I cannot come to the seminar this afternoon, I have to collect my daughter from school. In this case, the presupposition that is common belief of both parties (myself and my colleague) is that I have a daughter. I presuppose that I have a daughter and that my colleague believes that I have a daughter. My colleague presupposes that I have a daughter and that I believe that I have a daughter. Accommodation, or informative presupposition, would be required in a situation where my colleague does not know that I have a daughter before the speech act and comes to know that I have a daughter after the speech act. In this case, my colleague would infer that I have a daughter after the speech act if she believes that I am being honest. In this case, she will add the presupposition that I have a daughter to the common ground after the speech act. The speech act, the utterance, is what Stalnaker calls a 'manifest event' (2002, 708), an event that is mutually recognised to have occurred by both parties in the conversation. 
Stalnaker notices that in some cases what is presupposed may be different from what participants in the conversation believe. A more general notion of acceptance is therefore needed. On this view, acceptance is a propositional attitude that encompasses beliefs and other attitudes that may contrast with belief, such as supposition, presumption, assumption, and, as I will argue, make-believe. Acceptance is an attitude one party in a conversation assumes, perhaps for a limited time and only in the context of the conversation, when treating a proposition as true for a given purpose, ignoring the possibility that it may, in fact, be false. In the history class, teacher and students discuss the religious practices of ancient Rome and claim that the Romans worshipped Juno. Neither the teacher nor the students believe that Juno exists, yet they presuppose that there was such a goddess. They accept that Juno exists, ignoring the falsity of this proposition for the purpose of the conversation. It is common ground that Juno exists, and they believe that they accept that Juno exists, and they believe that all believe that all accept that Juno exists, etc.

Coherently with this framework, Sainsbury (2010) develops an account of fictional discourse and fictional truth in terms of acceptance and presupposition relative truth. On this view, we can evaluate the Juno sentence as true relative to the shared presupposition that there is such a goddess as Juno, which we know to be false. Similarly, we can evaluate a sentence like 'Desdemona is a Venetian beauty' with respect to the presupposition that there is such a Venetian beauty as Desdemona, which we accept (without believing it) for the purpose of engaging with the fiction. Sainsbury argues that the notion of presupposition-relative truth is independent of fiction, and this is an advantage of the view because 'it's not an ad hoc device designed to insulate an irrealist [read: antirealist] from problems special to fiction' (Sainsbury 2010, 146).

Another advantage of this proposal is that the notion of acceptance naturally extends to other types of discourse about fiction. Consider a comparison between fiction and reality such as 'Desdemona is a Venetian beauty, and she is more famous than any other real Venetian beauty'. If we regard the comparative sentence as true, presumably we do it with respect to the presupposition that Desdemona exists. This, however, would imply that her fame is greater than itself. Sainsbury's solution is to recognise that most 
uses of 'real' bring in some kind of metaphysical contrast, and that in this case the contrast is between reality and fictionality. The comparison is between a fictional character and real individuals. And while the realist would interpret it in terms of absolute truth, the antirealist would interpret it in terms of truth relative to the presupposition that there are fictional characters, which she would accept without believing.

While Sainsbury presents his antirealist account as alternative to Walton's theory of fiction as make-believe, I see it as one that can be specified in a way that makes it compatible with it. The propositional attitude of acceptance encompasses belief and other propositional attitudes that may contrast with belief. Acceptance is a neutral stance that one or more parties in a conversation hold toward a proposition in cases where they know that the proposition is true, in cases where they know that it is false, ad even in cases where they do not know whether the presupposed proposition is true or false (for example, agnostics may find themselves in the latter situation when they engage in conversations about god). As such, acceptance is too broad to capture the specificity of our characteristic attitude toward fiction. As stated above, standard theories of fiction define it in terms of imagination or make-believe. And Stalnaker recognises that pretence could be one of the specifications of acceptance. So, what we need is a specification of acceptance in its imaginative variety.

The notion of imagination that is relevant in this context, and that is compatible with Stalnaker's (and Sainsbury's) notion of acceptance, is propositional imagination, which is an ability to entertain alternative (possible or impossible) states of affairs, scenarios and situations, with or without forming a mental image. This is an attitude that is typically characterised by three minimal core features emerging from the current literature on imagination in cognitive science and philosophy of mind, freedom, quarantining, and mirroring.

Imagination manifests freedom in virtue of its being typically unconstrained by reality (Currie and Ravenscroft 2002; Nichols and Stich 2000; Velleman 2000). This feature provides the key criterion for the specification of the imaginative variety of acceptance as distinct from belief. To believe that $p$ is to hold $p$ as true at the actual world, and whether the actual world makes $p$ true or false is not up to us. To imagine that $p$, however, does not 
commit us to the truth of $p$. We can imagine spontaneously, in dream and daydreams, without guiding the imagination in a conscious way. Or we can imagine at will, as when we engage in the activity of supposition and counterfactual reasoning for the purpose of exploring alternative scenarios. When these activities involve props, they become games of make-believe involving participants who together can make up their own rules. This fits well with the practice of story-telling, which combines a spontaneous imaginative effort (often described as inspiration) with a guided imaginative effort of conscious construction of a story through the generation of a text, the prop. In standard cases, the audience's imaginings will be encouraged and guided by the author's activity of storytelling via the mediation of the text.

Imagination manifests mirroring when it carries inferential commitments that are analogous to those carried by belief (Gendler 2003; Leslie 1987; Perner 1991; Nichols and Stich 2000; Nichols 2004, 2006). As propositional attitudes, belief and imagination can engage the same inferential mechanisms of reasoning taking propositions as their inputs. If I believe that $p$, and I believe that if $p$ then $q$, then I believe that $q$. Similarly, if I imagine that $p$, and I imagine that if $p$ then $q$, then I imagine that $q$. The inferences we make when we believe and when we imagine a certain proposition depend on background assumptions and on the specific aims and interests that direct our reasoning. Thus, a realistic story naturally imports many factual truths from the actual world, based on our shared knowledge of reality. An epic poem imports the mutual beliefs of the particular society where the poem originates. A fantasy story relies on different sets of background knowledge based on the particular rules of this genre. Some otherperhaps more interesting - cases rely on the cultural background of the interpreter, and may become the subject of disputes and controversies among literary critics, as in the examples of critical disagreement mentioned above.

Imagination manifests quarantining to the extent that its content is typically sealed off from belief (Gendler 2003; Leslie 1987; Nichols and Stich 2000; Perner 1991). That is, imagining that $p$ does not entail believing that $p$. More generally, imaginings prompt affective responses and desires that are limited to a particular episode of imagination and they do not guide action in the real world. When reading Tolstoy's Anna Karenina, we may 
feel sorry for Anna and we may even want that she not dies. But these emotions and desires do not motivate us to act in any of the ways we would expect in normal circumstances. Moreover, fictional presuppositions are not apt for transformation into belief. And it is often inappropriate to explicitly cancel an imagined presupposition, because objecting to a story on the grounds of untruth is to cancel a presupposition that no one (unless misinformed) was going to adopt. Quarantining, however, does not imply that nothing of real-world relevance can be learned from an episode of imagination. We can learn many historical facts from reading Gore Vidal's historical fiction Julian (which recounts the rise and rule of the Roman emperor Julian) if we export the relevant information from the imaginative context created by the novel onto reality.

In sum, imagination is a variety of acceptance that is distinct from belief and that is characterised by three main features, freedom, mirroring and quarantining. More specific varieties of propositional imagination can be spelled out in terms of more specific conditions. ${ }^{17}$ In particular, Walton characterises make-believe as a social imaginative activity involving the use of props. This type of imagination is not only a cognitive ability, but an imaginative activity involving different parties who can share the same imaginings via the use of props. These imaginings constitute the intersubjective, interpersonal meanings associated with fictional names and provide the foundation for the subjective meanings stored in the relevant mental files.

\section{The meanings of fictional names}

According to Millianism, names without referents do not have any semantic content. Yet fictional names seem to be fully meaningful. Now we can pull together the resources developed in the previous Sections to explain how the proposed account of the meaningfulness of names can satisfy the five desiderata identified in Section 2.

Storytelling is a communicative effort between the author of fiction and the audience. The author prescribes the audience to imagine in certain ways.

17 See Salis and Frigg (2020) for possible further specifications. 
The audience imagines accordingly through the recognition of the author's prescriptions to imagine. This recognition is afforded by the use of props, which are ordinary objects that are publicly and intersubjectively available to participants in games of make-believe. In particular, literary works of fiction are props that were created by their author for the specific purpose of encouraging certain imaginings. They are representations that afford and constrain an audience's imaginings in virtue of their being concrete and intersubjectively available objects. The concrete character of a literary work of fiction is explained in terms of its smallest component units, particular marks on paper (or on a screen), which compose meaningful linguistic expressions and constitute the larger unit that is the text. Fictional names - or, better said, concrete instances thereof - are some of the meaningful linguistic expressions functioning as props within the larger prop that is the text. Their uses in fictional discourse support and encourage imaginings about fictional entities even though there are no such entities. Like all props, fictional names are perceptible entities that are originally created for the purpose of encouraging certain imaginings. In other words, they are representations (in Walton's sense) that are mutually recognised by participants in the communicative effort in virtue of their concrete character.

As argued above, fictional names do not contribute anything to the truth-conditional content of sentences involving them. This poses a problem for Millianism, which claims that the meaning of a name is exhausted by its individual referent. Explaining the meaningfulness of fictional names coherently with this view requires an appeal to two further pragmatic types of meaning, intersubjective and subjective. Intersubjective meaning is cached out in terms of the notion of common ground. Subjective meaning is cached out in terms of the notion of mental files.

Let us consider an example to illustrate these ideas in more detail. Stevenson's The Strange Case of Dr Jekyll and Mr Hyde begins with the following sentence:

Mr. Utterson the lawyer was a man of a rugged countenance that was never lighted by a smile; cold, scanty and embarrassed in discourse; backward in sentiment; lean, long, dusty, dreary and yet somehow lovable. 
Participation in the communicative effort initiated by Stevenson's storytelling requires imaginatively entering into the presupposition that the story told is true, and then speaking under that presupposition. Coherently with the author's prescriptions, the attitude an audience has toward that presupposition is imagination. The reader may fail to grasp some of the prescribed imaginings, so we cannot define reader's and author's engagement in the same make-believe as determined by the assumption of exactly the same set of presuppositions. What ultimately guarantees that readers engage in the same make-believe is that they defer to the author's storytelling. In the example, what is required is that they defer to Stevenson's activity of storytelling.

The author of fiction uses fictional names as props that signal which presuppositions are in place. When reading the fiction, sentence after sentence, chapter after chapter, the information flow initiated by Stevenson is accumulated into the set of presuppositions in place in the specific conversational background created by the story. Among these presuppositions are those triggered by fictional names. In the example above, recognising Stevenson's prescription to imagine requires presupposing that Mr Utterson exists. Both Stevenson and we, the readers, know that there is no particular man referred to by that name. Yet we add the proposition that Mr Utterson exists to the common ground. It is common ground that Mr Utterson exists, and we believe that we imagine that Mr Utterson exists, and we believe that all believe that all imagine that Mr Utterson exists, etc. Moreover, when reading the full sentence, we gather further information about $\mathrm{Mr}$ Utterson that we add to the common ground. For example, we add the propositions that Mr Utterson was a lawyer, that he was a man of a rugged countenance that was never lighted by a smile; that he was cold, scanty and embarrassed in discourse; that he was backward in sentiment; that he was lean, long, dusty, dreary and yet somehow lovable. All these are part of the common ground.

Of course, no individual reader will be able to store all that information in the common ground of the story. When reading about Mr Utterson, individual readers cluster the information they gather from the story in particular mental files. The information associated to the name Mr Utterson is stored in a mental file labelled with that very name. Each time a reader 
meets that very name in the story or in conversations about Mr Utterson, she deploys the mental file labelled with that name. The information she associates with the name may be incomplete, or even inaccurate, or it may be integrated with further information that was not originally included in the story. For example, a reader with good imagistic abilities may enrich the information provided by Stevenson with mental images in different sensory modalities. These additions, however, are not part of the common ground, but only of the particular file the reader associates with the name. This is coherent with the subjective and idiosyncratic ways in which speakers gather, interpret, enrich, remember or even misremember information afforded by fictions.

Coherently with mirroring, the information that is part of the story and that enters the common ground can be integrated via further principles of generation of the kind indicated above. This usually requires that both author and audience share the relevant principles. Yet, this may not always be possible. Literary fictions are a sort of delayed form of communication, where the author tells a story to an audience that may receive it decades, centuries or even millennia after the original act of storytelling. And controversies about the correctness or the relevance of particular interpretations are often left unsolved. And this is how things are and should be.

Coherently with quarantining, imaginings are non-committal. While everything that Stevenson says involves the relevant presuppositions, and the conversation as a whole is sensible only if it is understood as committed to those presuppositions, we do not commit to the presuppositions in a way that carries over to contexts outside the scope of the fiction. Also, our dispositions are not to take seriously the possibility that we could come to believe what is currently imagined. When we read fiction, we are not deceived by the author's storytelling.

Fictional names can be used in intra-fictional discourse and extra-fictional discourse. With the exception of meta-fictional statements, which involve serious assertions and an attitude of belief, most other cases can be interpreted as involving conniving uses of language and an attitude of imagination. Thus, conniving uses of fictional names in storytelling, fictional reports and participatory criticism trigger the usual presupposition (e.g., there is such an individual as Mr Utterson), which is imagined by speaker 
and audience in the relevant games of make-believe (authorised in the first two instances, unofficial in the third). Similar treatment applies to cases that are usually taken as evidence for fictional realism. For example, an utterance of 'Mr Utterson is a fictional character' involves a conniving use of the name 'Mr Utterson', which triggers the presupposition that there is such an individual as Mr Utterson for the purpose of cancelling it with the predicate 'is a fictional character.' And this is tantamount to convey the proposition that Mr Utterson does not exist. An utterance of 'Charlotte Brontë created Jane Eyre' involves a conniving use of the name 'Jane Eyre,' which triggers the presupposition that there is a fictional character such as Jane Eyre, but also the presupposition that Charlotte Brontë wrote a fictional story about a woman called Jane Eyre. One who does not know that Charlotte Brontë wrote a fictional story about a woman called Jane Eyre will learn this after the speech act, if she takes the speaker to be honest. In this case, we have a case of accommodation. With some flexibility, similar interpretations can be provided for similar cases depending on the context of utterance and mental states of participants in the conversation.

The account I just sketched clearly satisfies the two theoretical principles of parsimony and uniformity. It is parsimonious because it does not require the postulation of any fictional entities. It is uniform because it offers the same semantic interpretation of fictional names as rigid nondesignators throughout their uses in different types of fictional discourse. Furthermore, the account has the resources to satisfy the three conditions related to the problem of the intentionality of thought and discourse about fictional characters.

Let us start from the aboutness condition. We habitually think about fictional individuals and other fictional entities as if they were ordinary objects and yet there are no such objects. How can we explain the intuition that our thoughts and discourse about fictional characters are about something if there is no individual object to think about? Mental files offer a plausible solution because they contribute an explanation to the problem of object-directed yet objectless thought. When thinking about Desdemona, we deploy a mental file associated to her name. As we have seen, mental files are mental representations that stand for individual objects, without incurring any ontological commitments to real objects. Mental files are 
organisation structures for the storage of information that someone takes to be about some particular object, independently of whether such an object exists. Mental files are usually associated with information that is about objects that exist. And so, it seems to us that whenever we deploy a mental file we think about a concrete object, even if there is no such object. Thoughts that seem to be about an object without there being one engage the same sort of cognitive resources as thoughts about concrete things. While there seems to be an object, this seeming object is just a construct of the imagination. And since imagination does not bring any ontological commitment, we can think about imaginary objects through mental files without committing to their existence.

An answer to the problem of counterfictional imaginings can build on similar resources. We not only think about fictional individuals as if they were concrete. We also engage in counterfictional imaginings about them. In other words, we imagine them as being different from the ways they are described in the original fictions. This usually involves changing some or most of their properties to explore the ways they could have been in some alternative, imagined scenarios distinct from the one specified by the fiction. Mental files explain how there seems to be an imaginary object that we can think about. Effectively, this seeming object is a construct of the imagination, without there really being one. In the imagination, however, we can explore and transform features of the imaginary object just like we would explore and transform features of a concrete object. What this actually means is that we only imagine to explore and transform the imaginary object. And we do this by manipulating the information associated to the mental file. We usually keep fixed a certain amount of information (a certain subset of predicates) associated to the mental file for Anna Karenina, and change some other information to explore possible alternative ways she could have been. What we really do is shifting, adding, or deleting information from the mental file for the imaginary object.

Finally, the account has also the resources to explain the problem of intersubjective identification. Speakers can disagree about certain features of fictional objects. But how can they seem to be talking about the same object if there isn't one? While mental files can explain aboutness and counterfictional imaginings with respect to individual speakers, they cannot 
explain how different speakers can disagree about the same object when this does not exist. Fictional names as props come to rescue here. Fictional names are publicly and intersubjectively available objects that stand for particular fictional entities without any ontological commitment to their existence. They afford the recognition of the social and intersubjective meanings that are in the common ground of a particular communication exchange. Speakers can add or subtract propositions from the common ground by manipulating the information that is made available by the use of the same name. It is in virtue of using the name 'Hamlet' that Bloom can disagree with Freud's interpretation of the same character. It is in virtue of their participation in the same name-using practice, the one initiated by Shakespeare in the homonymous play, that Bloom and Freud can disagree about the same fictional individual even if he does not exist.

\section{Conclusion}

The integrated account sketched here provides a plausible, pragmatic explanation of the intuitive meaningfulness of fictional names. The underlying assumption is that fiction is a communicative effort between authors and their audiences. Communication is a social activity that requires manifest and publicly accessible tools for the construction of intersubjective meanings. In fiction, these are the text of the story wherein fictional names are introduced. In Walton's terms, they are props that afford and constrain an audience's imaginings coherently with the author's activity of storytelling. Successful communication requires the notion of shared information, or common ground. This contributes to the intersubjective dimension of meaning afforded by fictional names, and it further provides the foundation for the subjective dimension of meaning that is spelled out in terms of the notion of mental files. On this account, fiction is a form of communication that grounds the mental representations of involved parties. The author of fiction tells a story that encourages certain imaginings via the use of intersubjectively available linguistic tools. These tools are created for the purpose of encouraging imagining in certain ways and provide the manifest basis for the acquisition of information that can be shared and stored in mental representations. The account is ontologically parsimonious and semantically uniform. Moreover, 
it provides the resources to explain key features of the intentionality of thought and discourse about fictional characters.

\section{References}

Adams, Fred and Robert, Stecker. 1994. "Vacuous Singular Terms." Mind \& Language 9: 387-401. https://doi.org/10.1111/j.1468-0017.1994.tb00314.x

Berto, Francesco. 2011. "Modal Meinongianism and Fiction: The Best of Three Worlds." Philosophical Studies 152: 313-34. https://doi.org/10.1007/s11098009-9479-2

Bloom, Harold. (ed.) 1999, Henrik Ibsen (Modern Critical Views), Philadelphia: Chelsea House Publisher.

Bloom, Harold. 2001. How to Read and Why. New York: Simon and Schuster New York.

Braun, David. 2005. "Empty Names, Fictional Names, Mythical Names." Noûs 39: 596-631. https://doi.org/10.1111/j.0029-4624.2005.00541.x

Castañeda, Héctor Neri. 1990. "Fiction, Perception, and Forms of Predication." In Thinking and the Structure of the World, edited by K. Jacobi and H. Pape, 268-84. Berlin-New York: de Gruyter.

Currie, Gregory. 1988. "Fictional Names." Australian Journal of Philosophy 66: 471-88. https://doi.org/10.1080/00048408812343531

Currie, Gregory 1990: The Nature of Fiction. New York: Cambridge University Press.

Currie, Gregory and Ravenscroft, Ian. 2002. Recreative Minds: Imagination in Philosophy and Psychology. Oxford: Oxford University Press.

Davies, David 1996. "Fictional Truth and Fictional Authors." British Journal of Aesthetics 36: 43-55. https://doi.org/10.1093/bjaesthetics/36.1.43

Eagle, Anthony. 2007. "Telling Tales." Proceedings of the Aristotelian Society 107: 125-47. https://doi.org/10.1111/j.1467-9264.2007.00215.x

Evans, Gareth 1982. The Varieties of Reference. Oxford: Clarendon Press.

Everett, Anthony 2007. "Pretense, Existence, and Fictional Objects." Philosophy and Phenomenological Research 74 (1): 56-80. https://doi.org/10.1111/j.19331592.2007.00003.x

Everett, Anthony 2013. The Nonexistent. Oxford: Oxford University Press.

Frege, Gottlob. 1892. "Über Sinn und Bedeutung." Zeitschrift für Philosophie und Philosophische Kritik, 100. Reprinted in Frege, Collected Papers, edited by B. McGuinness. Basil Blackwell, 1984.

Friend, Stacie. 2012. "Fiction as a Genre." Proceedings of the Aristotelian Society 92: 179-208. https://doi.org/10.1111/j.1467-9264.2012.00331.x 
Friend, Stacie. 2011. "The Great Beetle Debate: A Study in Imagining with Names". Philosophical Studies 153 (2): 183-211. https://doi.org/10.1007/s11098-009-9485-4

Friend, Stacie. 2014. "Notions of Nothing." In Empty Representations: Reference and Non-Existence, edited by Manuel García-Carpintero and Genoveva Martí, Oxford University Press.

García-Carpintero, Manuel. 2013. "Norms of Fiction Making." British Journal of Aesthetics 53(3): 339-57. https://doi.org/10.1093/aesthj/ayt021

Gendler, Tamar S. 2003. "On the Relation between Pretense and Belief." In Imagination, Philosophy, and the Arts, edited by Matthew Kieran and Dominic MacIver Lopes, 125-41. London: Routledge. https://doi.org/10.1093/acprof:oso/9780199589760.001.0001

Geurts, Bart. 2017. "Fictional Commitments." Theoretical Linguistics 43 (1-2): 5360. https://doi.org/10.1515/tl-2017-0003

Grice, Paul. 1969. "Vacuous Names." In Words and Objections, edited by Donald Davidson and Jaakko Hintikka, 118-45. Dordrecht: Reidel.

Kamp, Hans. 1990. "Prolegomena to a Structural Account of Belief and Other Attitudes". In Propositional Attitudes: The Role of Content in Logic, Language, and Mind, edited by A. Anderson and J. Owens, 27-90. Stanford: CSLI.

Kripke, Saul. 2013. Reference and Existence: The John Locke Lectures. Oxford University Press.

Kripke, Saul. 1980. Naming and Necessity. Oxford: Blackwell.

Lamarque, Peter and Olsen, Stein H. 1994. Truth, Fiction, and Literature: A Philosophical Perspective. Oxford: Oxford University Press.

Leslie, Alan. 1987. "Pretense and Representation: The Origins of 'Theory of Mind'." Psychological Review 94 (4): 412-26. https://doi.org/10.1037/0033295X.94.4.412

Lewis, David K. 1978. "Truth in Fiction." American Philosophical Quarterly 15: $37-46$.

Lewis, David K. 1986. On the Plurality of Worlds. Oxford: Blackwell.

Maier, Emar. 2017. "Fictional Names in Psychologistic Semantics." Theoretical Linguistics 43 (1-2): 1-45. https://doi.org/10.1515/tl-2017-0001

Mill, John S. 1843/2011. A System of Logic, Ratiocinative and Inductive: Being a Connected View of the Principles of Evidence, and the Methods of Scientific Investigation (Cambridge Library Collection - Philosophy). Cambridge: Cambridge University Press.

Millikan, Ruth. 1997. "Images of Identity: In Search of Modes of Presentation." Mind 106: 499-519. https://doi.org/10.1093/mind/106.423.499

Millikan, Ruth. 2000. On Clear and Confused Ideas. Cambridge: Cambridge University Press. 
Murez, Michael and Recanati, François. 2016. "Mental Files: An Introduction." Review of Philosophy and Psychology 7: 265-81.

https://doi.org/10.1007/s13164-016-0314-3

Nichols, Shaun. 2004. "Imagining and Believing: The Promise of a Single Code." Journal of Aesthetics and Art Criticism 62: 129-39.

https://doi.org/10.1111/j.1540-594X.2004.00146.x

Nichols, Shaun. 2006. "Just the Imagination: Why Imagining Doesn't Behave Like Believing." Mind and Language 21 (4): 459-74. https://doi.org/10.1111/j.14680017.2006.00286.x

Nichols, Shaun and Stich, Steven. 2000. "A Cognitive Theory of Pretense." Cognition 74: 115-47. https://doi.org/10.1016/S0010-0277(99)00070-0

Perner, Josef 1991. Understanding the Representational Mind. Cambridge: MIT Press.

Perry, John 2001. Reference and Reflexivity. Stanford, CA: CSLI Publications.

Priest, Graham 1997. "Sylvan's Box: A Short Story and Ten Morals." Notre Dame Journal of Formal Logic 38: 573-82. doi:10.1305/ndjfl/1039540770

Priest, Graham. 2005. Towards Non-Being. The Logic and Metaphysics of Intentionality. Oxford: Clarendon.

Rapaport, William. 1978. "Meinongian Theories and a Russellian Paradox." Nô̂s 12: 153-80. https://doi.org/10.2307/2214690

Recanati, François. 2012. Mental Files. Oxford: Oxford University Press.

Sainsbury, Mark. 2010. Fiction and Fictionalism. London: Routledge.

Sainsbury, Mark 2005. Reference Without Referents. Oxford: Oxford University Press.

Salis, Fiora. 2013a. "Fictional Names and the Problem of Intersubjective Identification." Dialectica 67 (3): 283-301. https://doi.org/10.1111/17468361.12031

Salis, Fiora. 2013b. "Fictional Entities." In Online Companion to Problems in Analytic Philosophy, edited by Jõao Branquinho and Ricardo Santos, Lisbon: Centre of Philosophy, University of Lisbon. http://hdl.handle.net/10451/10860

Salis, Fiora and Frigg, Roman. 2020. "Capturing the Scientific Imagination." Scientific Imagination, edited by Peter Godfrey-Smith and Arnon Levy. Oxford: Oxford University Press. https://doi.org/10.1093/oso/9780190212308.001.0001 Salmon, Nathan. 1998. "Nonexistence." Noûs 32 (3): 277-319.

Stalnaker, Robert C. 1973. "Presuppositions." Journal of Philosophical Logic 2: 447-57. https://doi.org/10.1111/0029-4624.00101

Stalnaker, Robert C. 1999. Context and Content. Oxford: Oxford University Press.

Stalnaker, Robert C. 2002. "Common Ground." Linguistics and Philosophy 25: 701-21. https://doi.org/10.1023/A:1020867916902 
Stock, Kathleen 2011. "Fictive Utterance and Imagining." Proceedings of the Aristotelian Society Supplementary Volume 85: 145-61. https://doi.org/10.1111/j.1467-8349.2011.00200.x

Stock, Kathleen. 2017. Only Imagine: Fiction, Interpretation and Imagination. Oxford: Oxford University Press.

Strawson, Peter F. 1974. Subject and Predicate in Logic and Grammar. London: Methuen.

Thomasson, Amie. 1999. Fiction and Metaphysics. New York: Cambridge.

Van Inwagen, Peter. 1977. "Creatures of Fiction." American Philosophical Quarterly 14 (4): 299-308.

Velleman, David. 2000. "The Aim of Belief." In The Possibility of Practical Reason, 244-81. Oxford: Oxford University Press.

Voltolini, Alberto. 2006. How Ficta Follow from Fiction. Dordrecht: Springer.

Walton, Kendall. 1970. "Categories of Art." Philosophical Review 79: 334-67.

Walton, Kendall. 1990. Mimesis and Make-Believe. Cambridge: Harvard University Press.

Woodward, Richard. 2011. "Truth in Fiction." Philosophy Compass 6 (3): 158-67. https://doi.org/10.1111/j.1747-9991.2010.00367.x 